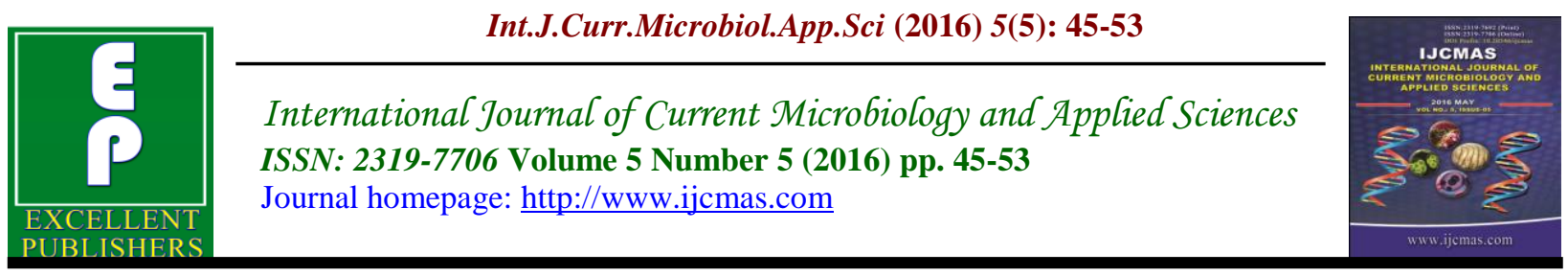

Original Research Article

http://dx.doi.org/10.20546/ijcmas.2016.505.005

\title{
Assessment of Biological Activities of Caffeine
}

\author{
Omkar Hemant Lele, Jinesh Anant Maniar*, Rohit Lalit Chakravorty, \\ Shashikant Prabhakar Vaidya and Abhay Shadashiv Chowdhary
}
Clinical Pathology Department, Haffkine Institute for Training, Research and Testing, Acharya Donde Marg, Parel, Mumbai 400012, India
*Corresponding author

\begin{abstract}
A B S T R A C T
Keywords

Caffeine,

Minimum

Inhibitory activity,

Subinhibitory

Concentration,

Proteolytic

activity,

Hemolytic

activity

Article Info

Accepted:

06 April 2016

Available Online:

10 May 2016

Caffeine (1, 3, 7 - trimethylxanthine) is a member of methylxanthines, widely used as biological active substance in the world and known for its various pharmacological effects. This study investigated antimicrobial activity of caffeine and the ability of Subinhibitory Concentration's (SIC's) of the same to interfere with the bacterial proteolytic activity, hemolytic activity and biofilm formation. Synergistic activity of caffeine was also studied with currently used therapeutic drugs against MRSA. Antimicrobial activity against four clinical isolates of MRSA namely MRSA1, MRSA2, MRSA3, MRSA 4 along with standard strain Staphylococcus aureus ATCC 6538 by broth dilution method. Caffeine inhibited bacterial growth at $5 \mathrm{mg} / \mathrm{mL}$ concentration. Subinhibitory concentrations (SIC's) thus selected were 1:2, 1:5 and 1:10 dilutions of MIC value i.e. $2.5 \mathrm{mg} / \mathrm{ml}, 1 \mathrm{mg} / \mathrm{ml}$ and $0.5 \mathrm{mg} / \mathrm{ml}$ respectively. There was a marked decrease in proteolytic activity in the range of $29 \%$ to $40 \%$, hemolytic activity in the range of $9 \%-19 \%$ ) and in biofilm formation $14 \%-21 \%$ in test organisms at $2.5 \mathrm{mg} / \mathrm{ml}$. Marked synergistic activities were found against Mupirocin, Amoxyclav, Chloramphenicol, Rrifampicin, and Linezolid. Such activity of caffeine could be crucial for topical applications of it. Further characterization of caffeine with respect to its anti-cancer activity, immunomodulatory activity and mode of action need to be carried out to evaluate the biological activities and medicinal utility of caffeine.
\end{abstract}

\section{Introduction}

Natural products are ancient promising sources used in traditional medicines. Plants have tremendous capacity to synthesize extraordinary secondary metabolites which possess different biological activities. Use of plant metabolites with antimicrobial activity can be of great importance as far as therapeutic treatments are concerned. Herbs of tea and coffee are the ones that have been studied earlier for the same (Olgica Stefanović and Ljiljana Comic, 2012).Tea and coffee are the most popular beverages all over the world and are being consumed since ancient times.

The biological properties of tea and coffee attributed to the presence of methylxanthins such as caffeine and phenolic compounds 
like catechins. Caffeine (1, 3, 7trimethylxanthine) is one of such compound present in coffee as well as tea. Amongst the biological activities of caffeine include immunomodulatory activity, central nervous system stimulatory activity, antimicrobial, anticancer and antioxidant activity. (Ghaleb Adwan and Mohammad Mhanna, 2008)

Caffeine is known to exhibits various biological functions. Some of the reported action of caffeine includes inhibition of phosphodiesters, which increases the level of intracellular cAMP, Caffeine has direct effect on intracellular concentration of calcium and indirect effect with response to membrane hyperpolarisation. Caffeine also blocks enzymes such as 5' nucleotidase and alkaline phosphatase. It has been reported that caffeine changes the inhibitory effect of antimicrobial agents. It influences several pathways that are involved in cellular response to DNA damage.

In recent times there has been lot of interest increasing about anti-infective activity of such bioactive compounds (Archana and Jayanthi Abraham, 2011).This can be an alternative approach to combat bacterial pathogens which selectively disrupt pathways that mediate virulence in them. The ability of such compounds to act synergistically with antibiotics could be a new approach to solve the problem of antimicrobial resistance.

Microorganisms attached to each other forming aggregates, producing their own extracellular matrix which helps in adhering this aggregates to particular surface such soil, medical instruments etc. This phenomenon is known as biofilm formations and the aggregates are known as biofilm (Rodney, 2001). Biofilm poses a serious medical threat because biofilm associated organism exhibits decreased susceptibility to antibiotic used for the treatment. Biofilm is known to cause chronic infection in which the causative microorganism couldn't be detected and antibiotics proves to be little useful in such cases (Bjarnsholt, 2013).

Staphylococcus aureus is a gram positive organism that is capable of causing wide range of diseases. This organism has ability to establish infection on skin as well as on mucous membrane. It also causes inflammation of bones and meninges. The major clinical manifestation observed in S.aureus is septicemia (Biswajit Batabyal et al., 2012). Penicillin and higher members of this group of antibiotics such as Methicillin are used for treatment of S.aureus infections. But certain strains have developed resistance to Methicillin and are therefore known as Methicillin resistant Staphylococcus aureus (MRSA). MRSA are resistant to many antibiotics and are more difficult to treat than ordinary S.aureus infection. The gene responsible for resistance to Methicillin in S.aureus is MecA gene which encodes for penicillin binding protein PBP 2A. MRSA has become a serious medical problem in terms of Hospital acquired infection as well as community acquired infection (Hafsat Ali Grema et al., 2015).

The objective of current study was to assess the biological activities of caffeine such antimicrobial, anti-infective, and synergistic activity with known antibiotics. The study also evaluates the effect of caffeine on biofilm formation.

\section{Materials and Methods}

\section{Materials}

Pure anhydrous caffeine powder was provided by Indo-German alkaloids, Mumbai, India. A stock solution of 10 $\mathrm{mg} / \mathrm{mL}$ was prepared in sterile distilled water. 


\section{Test Cultures}

S. aureus ATCC 6538 was procured from Himedia Laboratories Pvt. Ltd, Mumbai, India and was maintained in Department of Clinical Pathology, Haffkine Institute, Mumbai and 4 clinical isolates of Methicillin resistant Staphylococcus aureus collected from the Department of Microbiology, Grant Medical College and Sir. J.J group of Hospitals, Mumbai, India were used for the study.

\section{Methods}

Determination of Minimum Inhibitory Concentration (MIC) of Caffeine (Taylor; Charalampos Proestos et al., 2008; Srikandi Fardiaz, 1995)

The minimum inhibitory concentration was determined by broth dilution method. Cultures were grown overnight on Nutrient agar slant (Himedia Laboratories Pvt. Ltd). Then loop full of culture was transferred from the agar slants to Nutrient broth (Himedia Laboratories Pvt. Ltd) and incubated for 1-2 hours. Before performing the assay the density of suspension was adjusted to McFarland standards 0.5 . Caffeine concentration of $0.625 \mathrm{mg} / \mathrm{mL}, 1.25$ $\mathrm{mg} / \mathrm{mL}, \quad 2.5 \mathrm{mg} / \mathrm{mL}, 5 \mathrm{mg} / \mathrm{mL}$, and 10 $\mathrm{mg} / \mathrm{mL}$ were prepared in nutrient broth in the total volume of $2 \mathrm{ml}$ in a suspension tube. $50 \mu \mathrm{l}$ of bacterial suspension was inoculated to each tube and were incubated for 24 hours at $37^{\circ} \mathrm{C}$.

Results were noted at the end of incubation period. 4 different controls were also included in the study: 1) positive controlmedia+inoculum without caffeine, 2) negative control- media+ inoculum without caffeine (to be refrigerated), 3) Media control- only media and 4) Media caffeine control.
Synergistic Activity of Caffeine at SubMIC Level with Different Antibiotics (Joyce Elaine Cristina Betoni et al., 2006; CO Esimone et al., 2008; Ronen Ben-Ami et al., 2011)

Bacterial suspension of 0.5 McFarland standard was prepared using 24 hours old culture .Caffeine was incorporated into molten Mueller Hinton agar butt (Himedia Laboratories Pvt. Ltd) and then the medium was poured into the petri plate. Concentrations of caffeine used were $1 / 2^{\text {th }}$, $1 / 5^{\text {th }}$ and $1 / 10^{\text {th }}$ of the MIC value. The plates were swab inoculated with the organism and then different antibiotic discs were placed. The total of 11 antibiotics were used to test the synergistic activity of caffeine. The antibiotics disc used were Teicoplanin, Amoxicillin/clavulanate, Ciprofloxacin, Cephalexin, Nitrofurantoin, Mupirocin, Rifampicin, Gentamicin, Tobramycin, Linezolid, and Chloramphenicol. Plates were incubated at $37^{\circ} \mathrm{C}$ for 24 hours and zones of inhibition were measured using zone scale (Himedia Laboratories Pvt. Ltd) and compared with control plate without caffeine.

Assessment of Effect of Sub-MIC Level of Caffeine on Hemolytic Activity (Negri et al., 2010)

To assess the anti-hemolytic activity, 5\% blood agar plates (Himedia Laboratories Pvt. Ltd) containing sub-MIC levels of caffeine such $1 / 2^{\text {th }}, 1 / 5^{\text {th }}$ and $1 / 10^{\text {th }}$ of the MIC were prepared. $5 \mu \mathrm{l}$ of $1.5 \times 10^{8}$ cells $/ \mathrm{ml}$ bacterial suspension was spot inoculated on the plates, and plates were incubated at $37^{\circ} \mathrm{C}$ for 24 hours. At the end of incubation period halo zone/clear zone was calculated and percentage reduction in haemolysis activity was measured by comparing with control plate without caffeine and considering control plate to be showing 100\% activity. 


\section{Assessment of Effect of Aub-MIC Level of Caffeine on Proteolytic Activity}

Anti-proteolytic activity was evaluated using 5\% milk agar plate containing sub-MIC levels such as $1 / 2^{\text {th }}, 1 / 5^{\text {th }}$ and $1 / 10^{\text {th }}$ MIC of caffeine. The plates were spot inoculated by $5 \mu \mathrm{l}$ of bacterial suspension of 0.5 McFarland standard, and incubated at $37^{\circ} \mathrm{C}$ for 24 hours. At the end of incubation period halo zone/clear zone was calculated and percentage reduction in proteolytic activity was measured by comparing with control plate without caffeine and considering control plate to be showing $100 \%$ activity.

\section{Determining Effect of Sub-MIC Level of Caffeine on Biofilm Formation (Naoko Wakimoto et al., 2004; Djordjevic et al., 2002; Australian Broadcasting Corporation, 1997).}

Brain Heart Infusion Broth (Himedia Laboratories Pvt. Ltd) was used to study of biofilm formation. Loop full of 24 hour old culture was transferred from the Nutrient agar slants to nutrient broth and incubated for 1-2 hours and adjusted to 0.5 McFarland standards. This assay was performed in 96 well plate, were each well received $200 \mu 1$ of different sub-MIC levels $\left(1 / 2^{\text {th, }} 1 / 5^{\text {th }}\right.$ and $1 / 10^{\text {th }}$ ) of caffeine in Brain Heart Infusion Broth. Positive control and medium control were also put in parallel. $50 \mu \mathrm{l}$ culture was added to each well and incubated for 24 hours. After incubation, plates were removed and then washed thrice with sterile distilled water $(\mathrm{D} / \mathrm{W})$. Then plates were air dried and stained with $1 \%$ Crystal Violet and kept for 15 minutes. After 15 minutes, the plate was washed thrice with sterile $\mathrm{D} / \mathrm{W}$ and air dried. $70 \%$ ethanol was added for elution. Absorbance at $650 \mathrm{~nm}$ was recorded on multimode reader (Biotek Instrument Pvt. Ltd). Results were compared with positive control and percentage reduction would be noted considering positive control to show $100 \%$ effect.

\section{Results and Discussion}

The results show that caffeine powder possessed potential antimicrobial activity against S. aureus, and MRSA clinical isolates. Interestingly caffeine inhibited MRSA growth at $5 \mathrm{mg} / \mathrm{ml}$ (Table No-1).

Caffeine also showed significant synergistic activity with the tested antibiotics. Maximum synergistic activity was observed at $2.5 \mathrm{mg} / \mathrm{ml}$ caffeine concentration, followed by less activity at $1 \mathrm{mg} / \mathrm{ml}$ and least activity was observed at $0.5 \mathrm{mg} / \mathrm{ml}$ (Figure No. 1). Caffeine showed best synergistic activity with Mupirocin, Amoxyclav, Chloramphenicol, Rifampicin, and Linezolid antibiotics when tested against $S$. aureus and MRSA.

Subinhibitory concentration thus selected were $1 / 2$ th, $1 / 5^{\text {th }}$ and $1 / 10^{\text {th }}$ of MIC value i.e. $2.5 \mathrm{mg} / \mathrm{ml}, \quad 1 \mathrm{mg} / \mathrm{ml}$ and $0.5 \mathrm{mg} / \mathrm{ml}$ respectively. Effect of caffeine on hemolytic activity showed maximum reduction of $19 \%$ for S. aureus ATCC 6538. Reduction in the hemolytic activity was best observed at $2.5 \mathrm{mg} / \mathrm{ml}$ of caffeine. At $2.5 \mathrm{mg} / \mathrm{ml}$ of caffeine, among the MRSA clinical isolates, the maximum reduction in hemolytic activity was observed for isolates-1 which was $18.18 \%$ followed by MRSA clinical isolate-2, i.e. $14.28 \%$ reduction. The MRSA clinical isolate- 3 showed $10.52 \%$ reduction in hemolytic activity and the least percentage reduction was seen in case of MRSA clinical isolate - 4 which was 9.19 (Figure No-2).

Effect of caffeine on proteolytic activity revealed maximum reduction up to $40 \%$ protease activity in MRSA clinical isolates 1 at $2.5 \mathrm{mg} / \mathrm{ml}$ while S.aureus ATCC 6538 
had reduction of $37.5 \%$ at $2.5 \mathrm{mg} / \mathrm{ml}$ of caffeine. The MRSA clinical isolate 2,3 and 4 showed 39.28\%, 29.16\%, 33.45\% reduction in the preteolytic activity at $2.5 \mathrm{mg} / \mathrm{ml}$ concentration of caffeine respectively. The maximum reduction in proteolytic activity was observed at $2.5 \mathrm{mg} / \mathrm{ml}$ of caffeine in all the test organisms (Figure No-3).

Biofilm formation assay reveled caffeine maximum inhibition of biofilm formation up to $17 \%$ in S.aureus, $21 \%$ in MRSA isolates at $2.5 \mathrm{mg} / \mathrm{ml}$ for MRSA clinical isolate -2 which was the highest inhibition observed among MRSA clinical isolates. This was followed by MRSA clinical isolate- 4 which showed $18.03 \%$ reduction in biofilm formation. MRSA clinical isolate 1 and 3 showed $14.51 \%$ and $14.03 \%$ reduction in biofilm formation respectively (Figure No4).

Caffeine is a promising compound because of its extensive application in pharmacological preparations, including analgesics, diet aids and cold/flu remedies. (8). The antibacterial role of caffeine may be due to the fact that caffeine inhibits synthesis of proteins and DNA by inhibiting the incorporation of adenine and thymidine. Furthermore, caffeine enhances genotoxicity after DNA damage. It has been shown that person who is a regular tea or coffee drinker is less susceptible to MRSA nasal carriage and other respiratory pathogens.

Table.1 Minimum Inhibitory Concentration of Anhydrous Caffeine Powder on Tested Bacteria

\begin{tabular}{|c|c|c|c|c|c|c|c|c|c|}
\hline \multirow{2}{*}{ Organism } & \multicolumn{5}{|c|}{ Dilutions (mg/mL) } & \multicolumn{5}{c|}{ Controls } \\
\cline { 2 - 10 } & 0.625 & 1.25 & 2.5 & 5.0 & 10.0 & Positive & Negative & Media & $\begin{array}{c}\text { Media }+ \\
\text { caffeine } \\
\text { control }\end{array}$ \\
\hline $\begin{array}{c}\text { S.aureusATCC- } \\
\text { 6538 }\end{array}$ & +++ & ++ & + & - & - & +++ & - & - & - \\
\hline $\begin{array}{c}\text { MRSA clinical } \\
\text { Isolate -1 }\end{array}$ & +++ & + & + & - & - & +++ & - & - & - \\
\hline $\begin{array}{c}\text { MRSA clinical } \\
\text { Isolate-2 }\end{array}$ & +++ & + & + & - & - & +++ & - & - & - \\
\hline $\begin{array}{c}\text { MRSA clinical } \\
\text { Isolate -3 }\end{array}$ & +++ & + & + & - & - & +++ & - & - & - \\
\hline $\begin{array}{c}\text { MRSA clinical } \\
\text { Isolate -4 }\end{array}$ & +++ & + & + & - & - & +++ & - & - & - \\
\hline
\end{tabular}

Key: 1$)+++=$ Heavy growth

2) $++=$ Moderate growth

3) $+=$ Low growth

4) $-\quad=$ No growth 
Figure.1 Synergistic Activity of Caffeine with Different Antibiotics

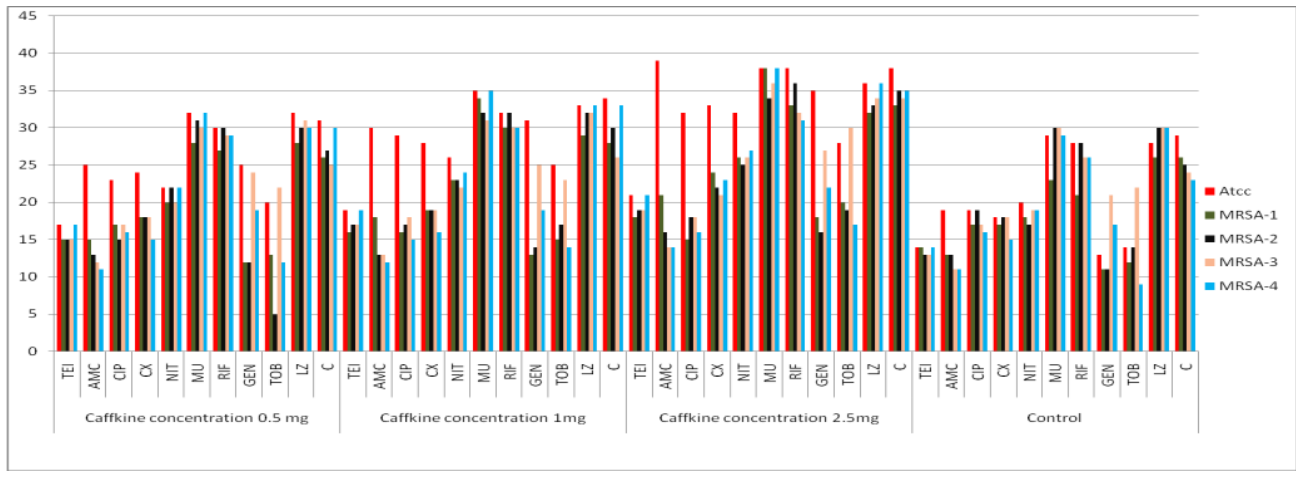

Figure.2 Percentage Reduction in Hemolytic Activity of S. aureus ATCC 6538 and 4 MRSA Clinical Isolates

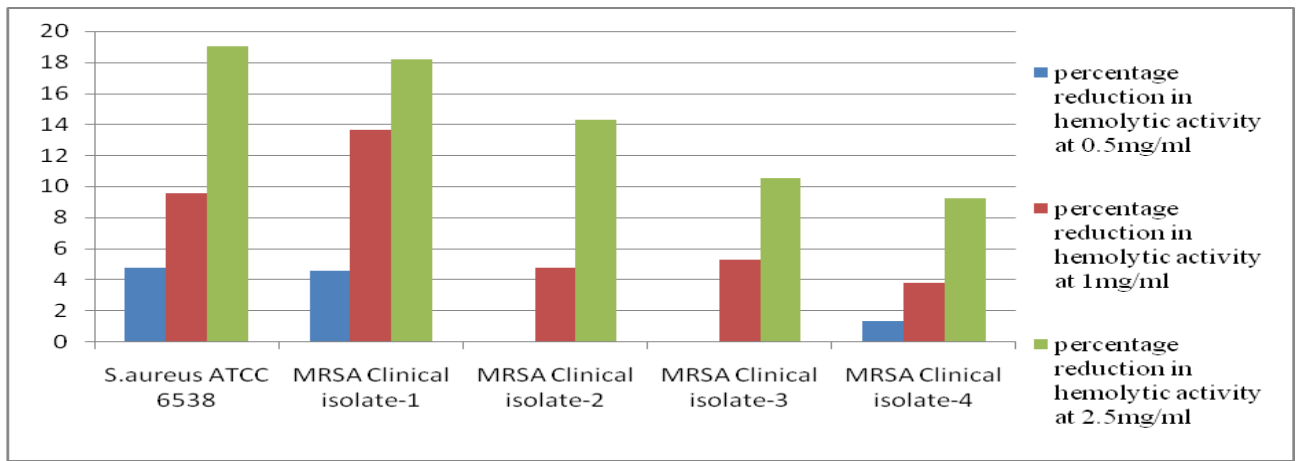

Figure.3 Percentage Reduction in Proteolytic Activity of S. aureus ATCC 6538 and 4 MRSA Clinical Isolates

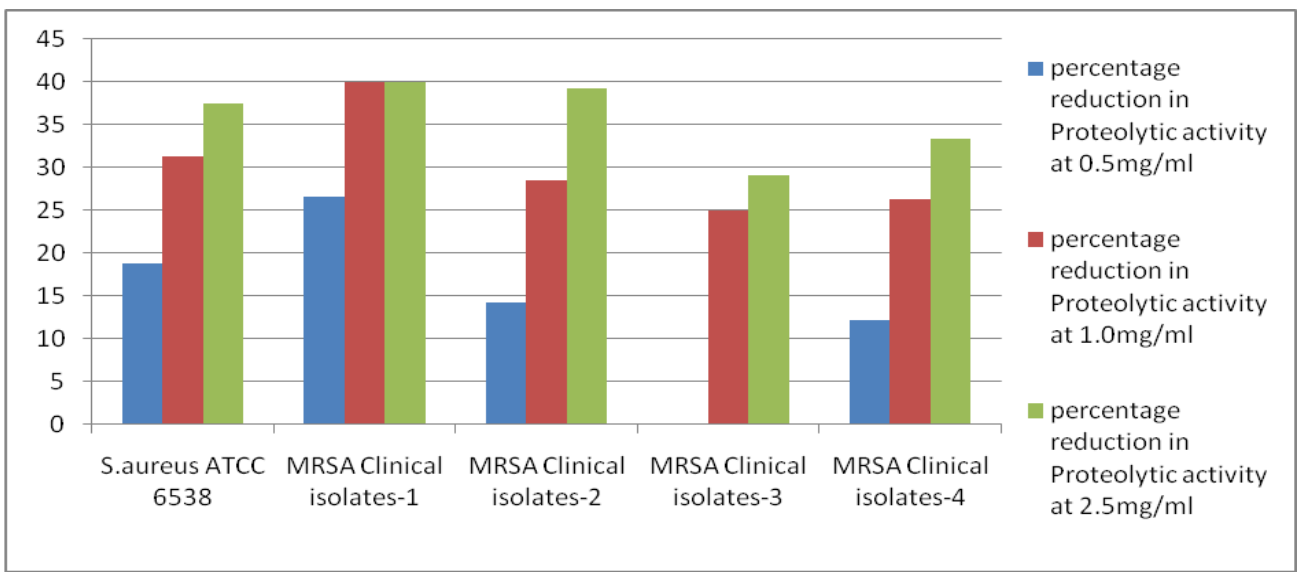


Figure.4 Biofilm Reduction in S. aureus ATCC 6538 and 4 MRSA Clinical Isolate

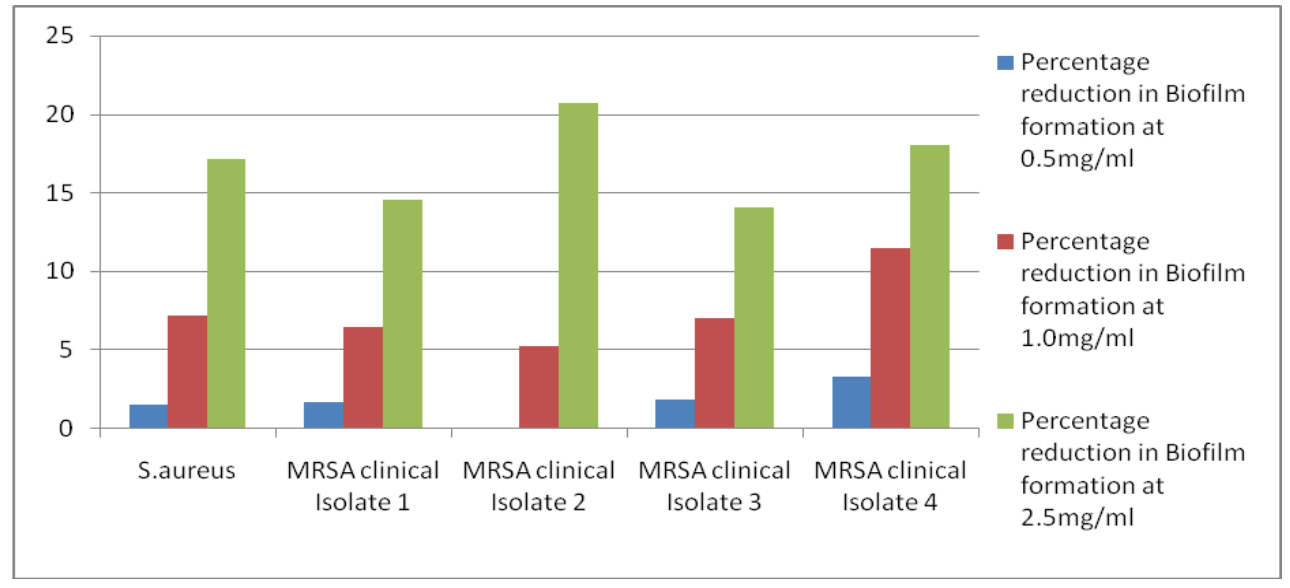

MIC of Caffeine and its Synergistic Activity with Standard Antibiotics

MIC was performed and it was observed that S.aureus and MRSA clinical isolates show no visible growth at $5 \mathrm{mg} / \mathrm{ml}$ concentration. This shows that caffeine is very active in preventing their growth at 5 $\mathrm{mg} / \mathrm{ml}$. Our results are matching with the earlier works (8) which also demonstrated similar results against test organisms. Since MIC was observed $5 \mathrm{mg} / \mathrm{ml}$, sub inhibitory concentrations were chosen as $1 / 2^{\text {th }}, 1 / 5^{\text {th }}$ and $1 / 10^{\text {th }}$ of the MIC. So we used 2.5 $\mathrm{mg} / \mathrm{ml}, 1 \mathrm{mg} / \mathrm{ml}$ and $0.5 \mathrm{mg} / \mathrm{ml}$ of caffeine. Caffeine in synergism with antibiotics has shown a significant effect against Staphylococcus aureus, and MRSA with respect to Mupirocin, Amoxyclav, Rifampicin, Linezolid and Chloramphenicol. Maximum synergistic activity was observed at $2.5 \mathrm{mg} / \mathrm{ml}$ caffeine concentration. The increase in the zone size of about $9 \mathrm{~mm}$, $20 \mathrm{~mm}, 9 \mathrm{~mm}, 10 \mathrm{~mm}, 8 \mathrm{~mm}$ for mupirocin, amoxyclav, chloramphenicol, rifampicin, and linezolid antibiotics respectively at 2.5 $\mathrm{mg} / \mathrm{ml}$ for S.aureus was observed. Ciprofloxacin however showed antagonistic activity when tested at all concentrations. Thus our assay demonstrated that caffeine shows synergistic activity with all the 11 antibiotics used in the study.

\section{Anti-infectivity Activity of Caffeine}

The anti-infective strategy that have been performed by us, was the unique study, first time reporting the effects of sub-MIC levels of caffeine on virulence factors and biofilm production. The effect of sub-MIC levels of caffeine on Hemolytic and Proteolytic activity showed concentration dependent inhibition. $35.87 \%$ average percentage reduction was observed at $2.5 \mathrm{mg} / \mathrm{ml}(1 / 2$ th MIC) for S.aureus and MRSA clinical isolates and in case of reduction in Hemolytic activity the average percentage reduction was 14.24 at $2.5 \mathrm{mg} / \mathrm{ml}$ caffeine concentration. The results obtained had a scientific potential and sub-MIC level at 2.5 $\mathrm{mg} / \mathrm{ml}$ shows maximum inhibition of the hemolysin and proteolysin produced by the organisms, followed by $1 \mathrm{mg} / \mathrm{ml}$ which possess good activity but less than 2.5 $\mathrm{mg} / \mathrm{ml}$ and lastly followed by $0.5 \mathrm{mg} / \mathrm{ml}$ which shows very less or no activity. Thus our main aim to inhibit virulence factor without killing the organisms (which would help in prevention of resistance development), has been successfully attained.

\section{Effect of Caffeine on Biofilm Formation}

Biofilm has been very problematic 
especially in hospitals in surgical equipments, burn patients, and various other places. Formation of Biofilm has been characterized by increased resistance of the organism towards external agents. This assay carried out has provided us promising results with caffeine inhibiting the biofilm formation. At $2.5 \mathrm{mg} / \mathrm{ml}$ (sub-MIC), we obtained the best result where biofilm reduction has been to a great extent with about $17 \%$ in S.aureus, $21 \%$ in MRSA. Thus caffeine is capable in prevention of biofilm formation. These studies showed that the antibiotics which are generally ineffective against biofilm and drug resistance microorganisms can show activity against them when used with caffeine.

\section{Acknowledgment}

The authors are grateful to Dr. Shital Vasave, Senior Scientific Officer and Mrs. Vibhuti Thakur, Scientific Officer, Department of Clinical Pathology, Haffkine Institute For Training, Research and Testing for providing technical guidance and to $\mathrm{Mr}$. Aurnagiri Subramanian for providing MRSA clinical isolates.

\section{References}

Olgica Stefanović, Ljiljana Comic. 2012. Synergistic antibacterial interaction between Melissa officinalis extracts and antibiotics. J. Appl. Pharma. Sci., 02: 01-05.

Ghaleb Adwan, Mohammad Mhanna. 2008. Synergistic Effects of Plant Extracts and Antibiotics on Staphylococcus aureus Strains Isolated from Clinical Specimens. Middle-East J. Sci. Res., 3: 134-139.

Archana, S., Jayanthi Abraham. 2011. Comparative analysis of antimicrobial activity of leaf extracts from fresh green tea, commercial green tea and black tea on pathogens. J. Appl. Pharma. Sci., 01(08): 149152.

Rodney, M., Donlan. 2001. Biofilm Formation: A Clinically Relevant Microbiol. Process Healthcare Epidemiol., CID, 33.

Bjarnsholt, T. 2013. The Role of Bacterial Biofilms in Chronic Infections. APMIS, 121(Suppl. 136): 1-51.

Biswajit Batabyal, Gautam, K.R., Kundu, Shibendu Biswas. 2012. MethicillinResistant Staphylococcus Aureus: A Brief Review. Int. Res. J. Biol. Sci., Vol. 1(7): 65-71.

Hafsat Ali Grema, Yaqub Ahmed Geidam, Galadima Bala Gadzama, James Agbo Ameh, Abubakar Suleiman. 2015. Methicillin Resistant Staphylococcus aureus(MRSA): A Review. Adv. Ani. Vet. Sci., Volume 3. Issue 2. Page 79.

Taylor, D., Gaines. "Methylxanthines: Determination of Synergistic and Antimicrobial Properties of Caffeine And its Metabolites against Staphylococcus aureus and Pseudomonas aeruginosa. Presented to Oklahoma Junior Academy Of Science.

Charalampos Proestos, Ioannis Spyridon Boziaris, Maria Kapsokefalou, Michael Komaitis. 2008. "Natural Antioxidant Constituents from Selected Aromatic Plants and Their Antimicrobial Activity against Selected Pathogenic Microorganisms." Biotechnol., 46(2): 151-156.

Srikandi Fardiaz. 1995. "Antimicrobial Activity of Coffee (Coffearobusta) Extract". Asian Food J., Vol. 10, No3.

Joyce Elaine Cristina Betoni, Rebeca Passarelli Mantovani, Lidiane Nunes Barbosa, Luiz Claudio Di Stasi, Ary 
Fernandes Junior. 2006. Synergism between plant extract and antimicrobial drugs used on Staphylococcus aureus diseases. Mem Inst Oswaldo Cruz, Rio de Janeiro, Vol. 101(4): 387-390

CO Esimone, FBC Okoye, CS Nworu, CO Agubata. 2008. In vitro interaction between caffeine and some penicillin antibiotics against Staphylococcus aureus. Trop. J. Pharma. Res., Volume 7, Issue 2.

Ronen Ben-Ami, Russell, E., Lewis, Dimitrios, P., Kontoyiannis. 2011. In vitro interactions among echinocandins against Aspergillus fumigatus: lack of concordance among methods. Med. Mycol., Volume 49. PP 285-288.

Negri, M.F., Faria, M.G., Guilhermetti, E., Alves, A.A., Paula, C.R., Svidzinski, T.I.E. 2010. "Hemolytic activity and production of germ tubes related to pathogenic potential of clinical isolates of Candida albicans." $J$. Basic and Appl. Pharma. Sci., Volume 31. Issue 1.

Naoko Wakimoto, Junichiro Nishi, Jalaluddin Sheikh, James, P., Nataro, JavSarantuya,
Mayumi Iwashita, KunihiroManago, Koichi Tokuda, Masao Yoshinaga, Yoshifumi Kawano. 2004. Quantitative Biofilm Assay Using a Microtiter Plate to Screen for Enteroaggregative Escherichia coli." Am. J. Trop. Med. Hyg., 71(5): pp. 687-690.

Djordjevic, D., Wiedmann, M., L. A. McLandsborough, 2002. "Microtiter Plate Assay for Assessment of Listeria monocytogenes Biofilm Formation." Appl. Environ. Microbiol., Vol. 68, No. 6.

What's your poison: caffeine. Australian Broadcasting Corporation. 1997. Retrieved 2009-08-03.

Eric, M., Matheson, Arch, G., Mainous, Charles, J., Everett, Dana, E., King. 2011. "Tea and Coffee Consumption and MRSA Nasal Carriage.” Annals Family Med., VOL. 9, NO. 4.

Neal, D., Freedman, Yikyung Park, Christian, C., Abnet, Albert, R., Hollenbeck, Rashmi Sinha. 2012. Association of Coffee Drinking with Total and CauseSpecific Mortality. Circulationaha, 115.017341. DOI: $\quad 10.1161$

\section{How to cite this article:}

Omkar Hemant Lele, Jinesh Anant Maniar, Rohit Lalit Chakravorty, Shashikant Prabhakar Vaidya and Abhay Shadashiv Chowdhary. 2016. Assessment of Biological Activities of Caffeine.Int.J.Curr.Microbiol.App.Sci. 5(5): 45-53. doi: http://dx.doi.org/10.20546/ijcmas.2016.505.005 